\title{
Copula-based modeling of hydraulic structures using a nonlinear reservoir model
}

\author{
Xin Wen ${ }^{1}$, Yunze Mao ${ }^{1}$, Qiaofeng Tan $^{1}$, Tian Jin ${ }^{1}$, Zhenni Wang ${ }^{1}$, and Ziyu Ding ${ }^{1}$ \\ ${ }^{1}$ Hohai University
}

November 16, 2020

\begin{abstract}
Multivariate flood frequency analysis has been widely used in the design and risk assessment of hydraulic structures. However, previous studies have mostly relied on the idealized linear reservoir model in which a linear routing process is assumed, and consequently the flood risk is likely to be over- or under-estimated. The present study proposes a nonlinear reservoir model in which the relationships of reservoir water level with reservoir volume and discharge are assumed to be nonlinear in order to more accurately describe the routing process as it takes into consideration the interactions between hydrological loading and different discharge structures. The structure return period is calculated based on the copula function and compared with that based on the linear reservoir model and the bivariate return period based on the Kendall distribution function. The results show that the structure return period based on the linear model leads to an underestimation of the flood risk under the conditions of high reservoir water level. For the same reservoir, linear and nonlinear reservoir models give quite different reservoir volume-water level and discharge-water level curves, and therefore they differ substantially in the sensitivity to flood events with different combinations of flood peak and volume. We also analyze the effects of the parameters involved in the reservoir volume-water level and discharge-water level relationships on the maximum water level at different return periods in order to better understand the applicability and effectiveness of the proposed method for different hydraulic projects.
\end{abstract}

\section{Hosted file}

manuscript.pdf available at https://authorea.com/users/376156/articles/493218-copula-basedmodeling-of-hydraulic-structures-using-a-nonlinear-reservoir-model

\section{Hosted file}

Table1.pdf available at https://authorea.com/users/376156/articles/493218-copula-basedmodeling-of-hydraulic-structures-using-a-nonlinear-reservoir-model

\section{Hosted file}

Table2.pdf available at https://authorea.com/users/376156/articles/493218-copula-basedmodeling-of-hydraulic-structures-using-a-nonlinear-reservoir-model 

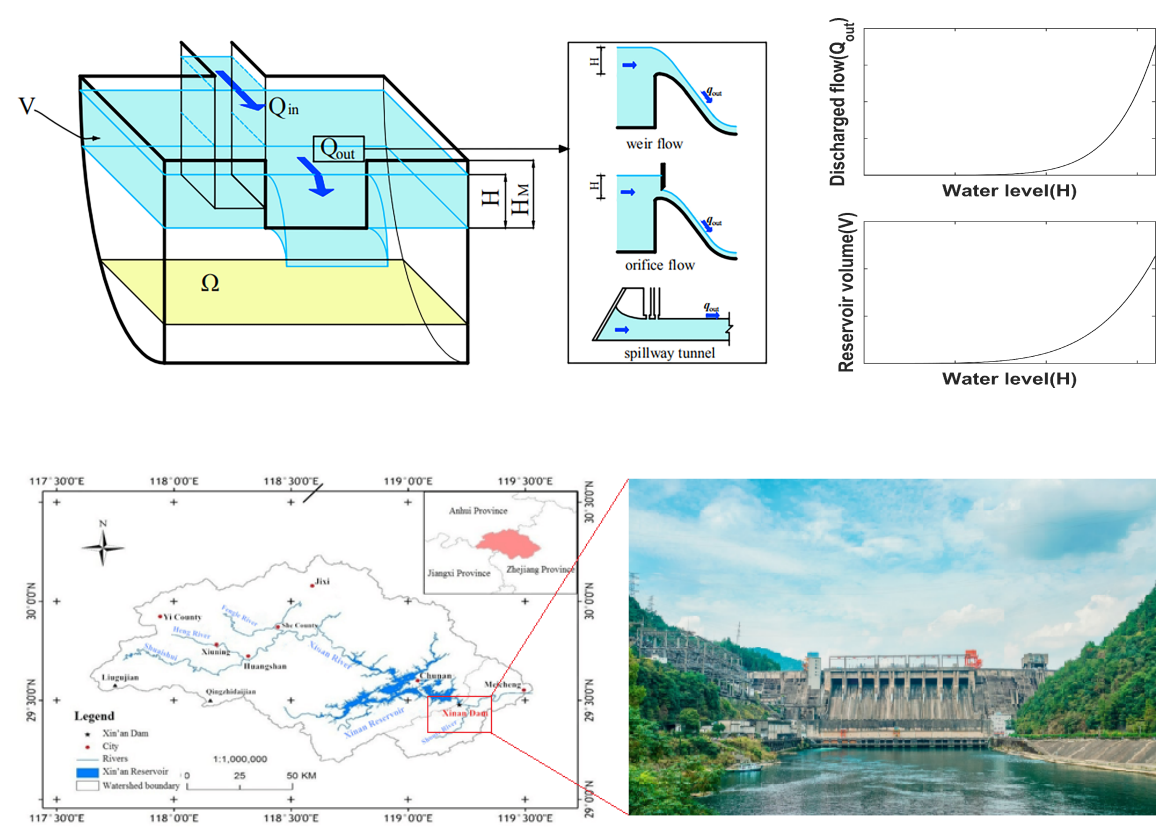

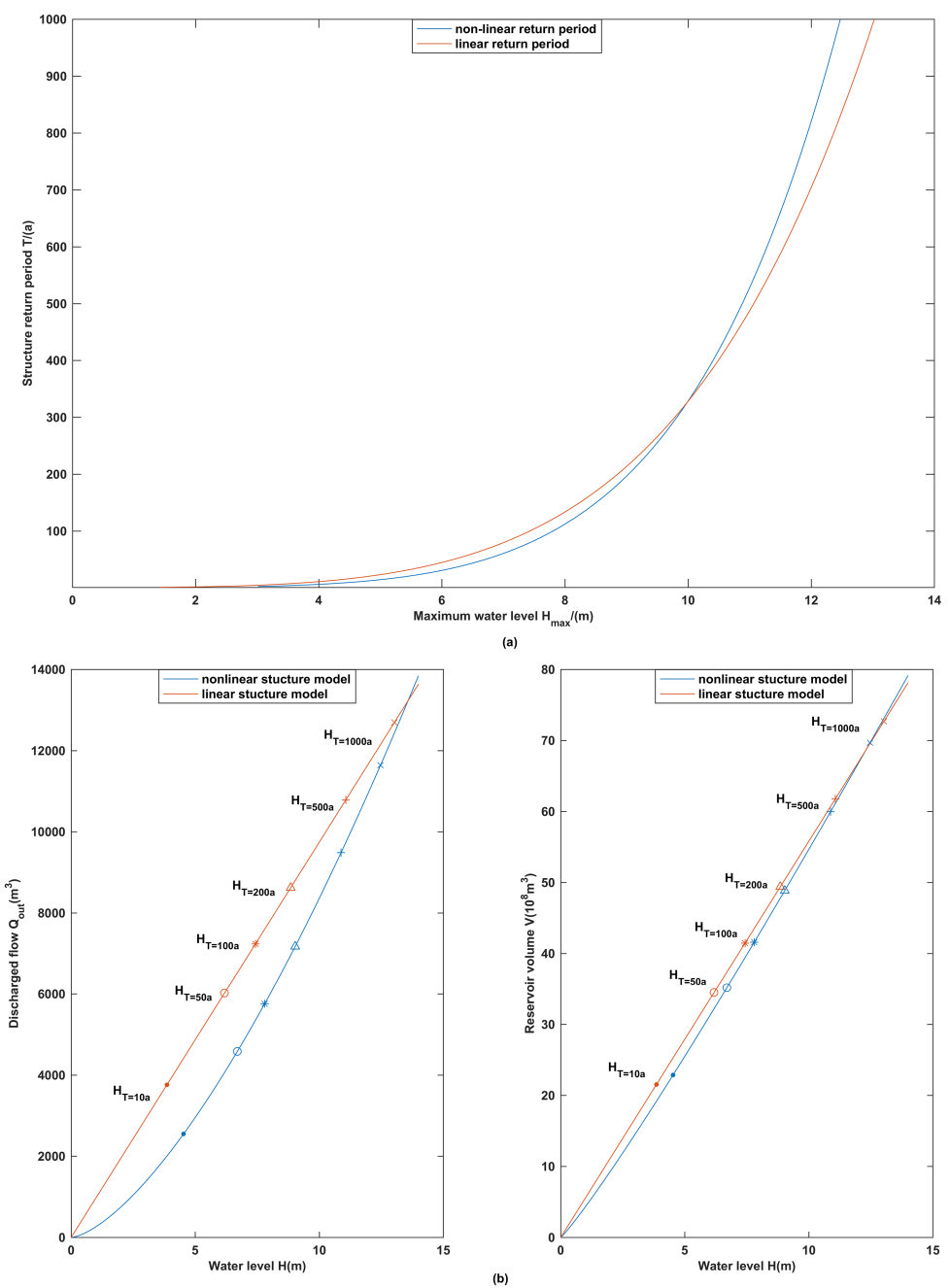


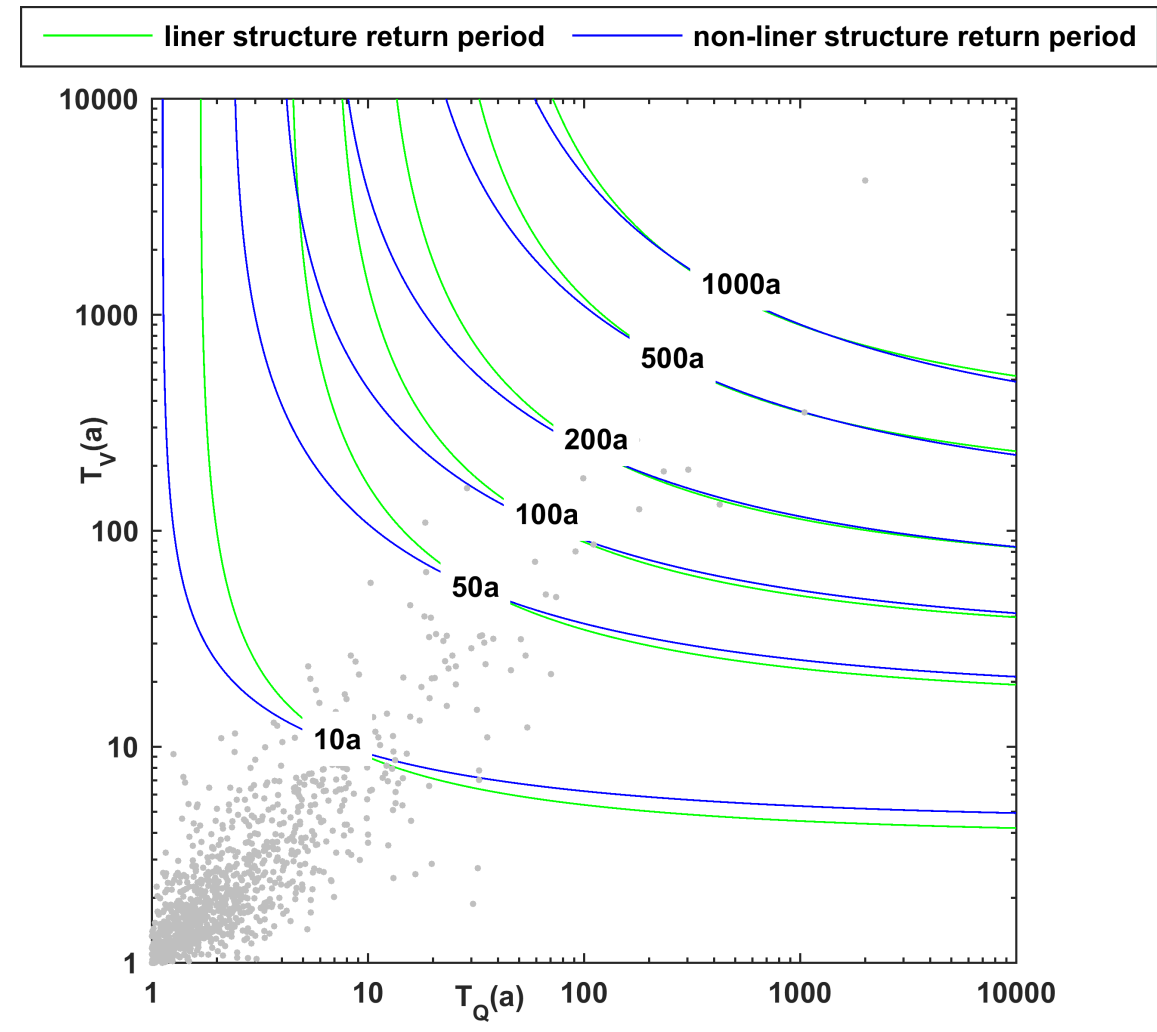



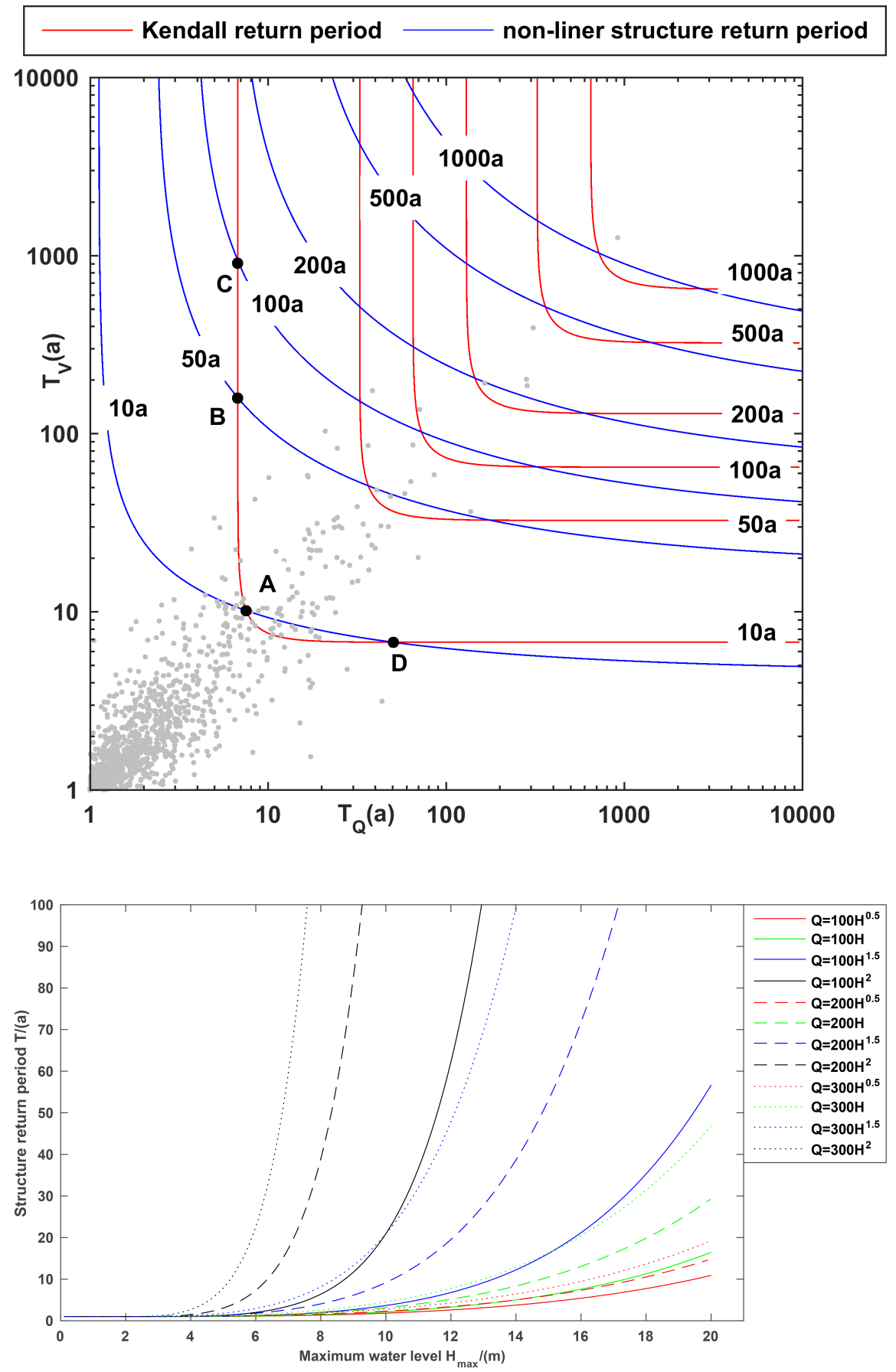


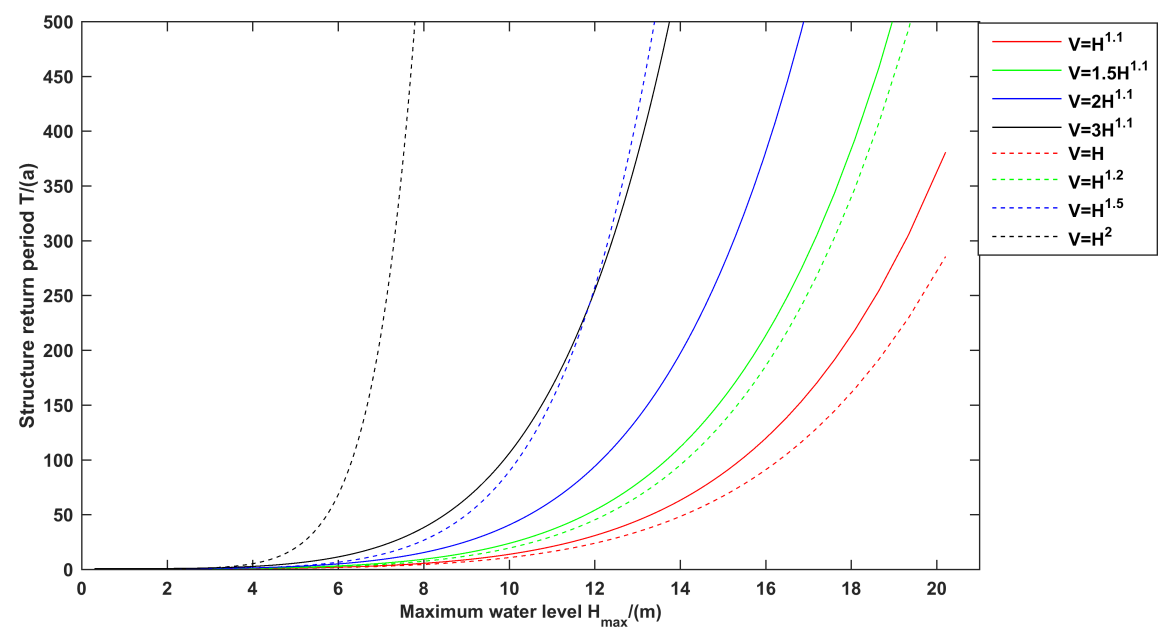

